This is the accepted manuscript of the article, which has been published in Drug and Alcohol

Dependence, 2020, 214, 108145.

https://doi.org/10.1016/j.drugalcdep.2020.108145

\title{
Grocery purchase data in the study of alcohol use - A validity study
}

Lintonen T, Uusitalo L, Erkkola M, Rahkonen O, Saarijärvi H, Fogelholm M, Nevalainen J

\begin{abstract}
Background: Alcohol use epidemiology is facing challenges as survey response rates decline. In addition, population surveys fail to capture a large proportion of alcohol consumed and are expensive to conduct. This study aims to aid in complementing traditional epidemiological methods by validate grocery purchase data in the research on population alcohol use.
\end{abstract}

Methods: The LoCard study subjects were loyalty card holders of a grocery retail co-operative, which possessed more than $45 \%$ market share in Finland. One third of those who consented to the analyses of their grocery purchases were presented a questionnaire including a Food Frequency Questionnaire on the web; $\mathrm{N}=11,818$ responded. The relationship between beer purchase frequency and self-reported beer drinking frequency was studied for association and agreement in different subgroups using crosstabulations and Poisson regression modeling.

Results: The association between beer purchase frequency and self-reported beer drinking frequency was good (Gamma=.556). The agreement between beer purchase frequency and drinking frequency was only fair (Kappa=.189). Limiting the data to those single adult households that reported making at least $61 \%$ of their grocery purchases from this grocery retailer and collapsing the frequency categories to three instead of six increased the agreement to good (Kappa=.463).

Conclusions: Information on beer purchase frequency from the loyalty card database can be used to rank people according to their drinking frequency and to estimate beer drinking frequency with fair to good accuracy, depending on what share of grocery purchases they make from the grocery retailer in question.

Keywords: alcohol; beer; drinking frequency; methodology; data collection; loyalty card data; validity

\section{Introduction}

Alcohol epidemiology is facing challenges as population survey response rates decline (e.g. Sierosławski et al., 2016). While studies utilizing clinical samples continue to provide information on people with alcohol use disorders, the study of population drinking habits suffers from people's decreasing participation in surveys. Alcohol sales statistics provide information on total consumption but cannot be used to analyze e.g. socio-demographic differences in drinking. Furthermore, population surveys fail to capture a large proportion of alcohol consumed and are increasingly expensive to conduct.

In Finland, the response rate to a nationally representative Drinking Habits Survey was initially over $90 \%$ in the 1960s but declined gradually to 60\% in the 2016 data collection (Mäkelä and Härkönen, 2017). Other alcohol use surveys representative of European populations exhibit similar response rates (Sierosławski et al., 2016). While statistical methods can be used to adjust the data to better represent the population, complex non-response weights do not seem to provide much added value in surveys on alcohol use (Tolonen et al., 2019). An estimate of population total alcohol consumption based on the 2016 survey covered less than $50 \%$ of the alcohol sold or imported to Finland (Mäkelä and Härkönen, 2017); recall and social desirability biases need to be carefully considered. 
Novel methods for data collection in epidemiology, such as digital tools and repositories (Kesse-Guyot et al., 2016; Mooney et al. 2015; Salathé, 2018; Tin et al., 2007) can be utilized to complement traditional survey and register data. Patient-generated data are increasingly used for health research purposes (Aledavood et al., 2019; Pietilä et al., 2018); automated collection can decrease information bias. Respondent selection bias is an issue, however: e.g. mobile health app users are younger, better educated and represent wealthier people (Carroll et al., 2017).

Grocery purchase data has been utilized in nutrition studies (Bandy et al., 2019). Studies have used panelbased data, with all grocery-purchase receipts scanned at home. However, this requires consistent efforts and long-term engagement from the participants (Appelhans et al., 2017). The issue of household versus individual food consumption has also been raised (Becker, 2001).

The total consumption of alcoholic beverages in Finland in terms of $100 \%$ alcohol was 8.7 liters per capita both in 2017 and 2018 (Yearbook of Alcohol and Drug Statistics 2019, 2020). Eighty-six percent of the recorded consumption was sold through retail outlets and the remainder through licensed serving. In 2018, beer accounted for $47 \%$ of retail alcohol sales. Beverages with more than $5.5 \%$ alcohol content (e.g. wine and spirits) were only available through monopoly stores and accounted for $23 \%$ of retail sales in terms of $100 \%$ alcohol.

The study aim was to validate grocery purchase data in the research on population alcohol use. We studied 1) the association between beer purchase frequency and self-reported beer drinking frequency to assess if purchase data can be used to rank people according to their beer drinking frequency (i.e. differentiate frequent drinkers from those drinking only rarely), and 2) the agreement between these measures to assess if purchase data can be used to estimate beer drinking. In addition, the relationship between beer purchases and drinking in population sub-groups was analyzed.

\section{Materials and methods}

\subsection{Setting and participants}

The LoCard study subjects were customer loyalty card holders $(\mathrm{N}=1,175,337)$ of the retail co-operative SGroup, which held over 45\% market share in Finland (Nevalainen et al., 2018). Cardholders with email addresses who consented to contacts for research purposes were asked to consent to analyzing their grocery purchases. Those who replied and consented $(\mathrm{N}=47,066)$ were randomly assigned to three different sets of questions with one set including the questions utilized here: demographic data and a food frequency questionnaire, FFQ (Korkalo et al., 2019). Three quarters responded and $\mathrm{N}=11,818$ answered the questions used in the current analyses. Details were described by Vuorinen et al. (2020).

\subsection{Measures}

Beer purchase days for six months preceding consent was used to calculate purchase frequency. Beer drinking frequency was obtained from the FFQ question "Thinking back on the past month, how many times have you eaten the following foods?", which included the item "Beer". The options were "none at all", "less than once a month", " 1 to 3 times a month", "1 or 2 times a week", " 3 to 5 times a week" and "daily or almost daily".

Demographic data were: sex (male/female), age (under 30 years, 30 to 59 years, 60 years or over), education (primary, secondary, Bachelors's degree, Master's degree), main activity (employed, unemployed, student, retired, other), the number of adults and children in the household, and selfreported degree of loyalty to the grocery retailer, i.e. the estimated percentage of groceries the respondent bought from the S-Group. 


\subsection{Data analysis}

Beer purchase and beer drinking frequency were considered as ordinal variables and were cross tabulated (Figure 1). The association was measured using Goodman and Kruskal's Gamma: zero indicating absence of association and 1 perfect association (Goodman and Kruskal 1954). Purchase days were coded into classes corresponding with the FFQ drinking frequency. Sufficient association between the two would indicate that purchase frequencies could be used to rank people according to drinking frequency. The agreement between purchase frequency and drinking frequency was studied using Kappa applying guidelines by Landis and Koch: $0-0.20$ slight, $0.21-0.40$ fair, $0.41-0.60$ moderate, $0.61-0.80$ substantial, and $0.81-1$ almost perfect agreement (Landis and Koch, 1977). An agreement plot (Bangdiwala and Shankar, 2013) illustrates the level of exact and partial agreement relative to the observed frequency (shade of blue within each rectangle in the plot) and an assessment of disagreement (deviation from the diagonal line in the plot; Figure 2).

The effect of sociodemographics on agreement were studied using a Poisson regression model with purchase frequency (in days) as the response variable, midpoint of the drinking frequency category as the offset term and the degree of loyalty as an explanatory factor. An intercept term close to zero would indicate good agreement between purchase frequency and drinking frequency. The regression coefficients represent the differences in agreement between the two levels of the explanatory variables (degree of loyalty and demographic variables).

\section{Results}

\subsection{Association between purchase frequency and drinking frequency}

The association between purchase frequency and drinking frequency was Gamma $=.556(95 \% \mathrm{Cl} .542, .570)$; beer purchase frequency strongly increased with beer drinking frequency (Figure 1).

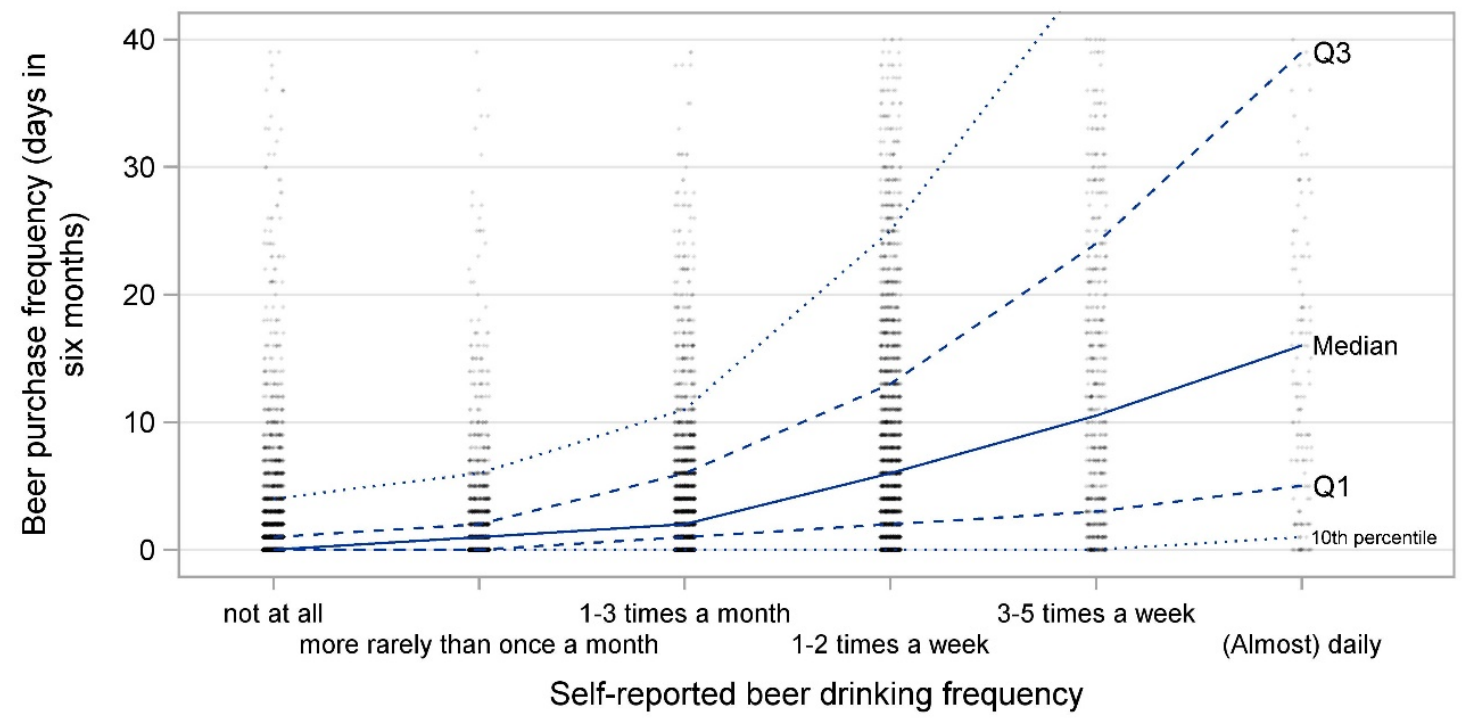

Figure 1. Beer purchase frequency during 6 months ( $y$-axis) by self-reported beer drinking frequency ( $x-$ axis). The 90th percentile (top dotted line) for those reporting (almost) daily drinking lies at 81 . Unadjusted associations.

\subsection{Agreement between purchase frequency and drinking frequency}


The agreement between purchase frequency and drinking frequency indicated slight agreement (Kappa $=.189 ; 95 \% \mathrm{Cl} .179, .199$ ). Exact matches amounted to $40 \%$, adjacent matches $47 \%$ and severe misclassification $13 \%$, which includes $0.2 \%$ cases in opposite categories. Less beer purchases than beer drinking occasions were found in $43 \%$ of the cases and more purchases than drinking in $17 \%$ of the cases.

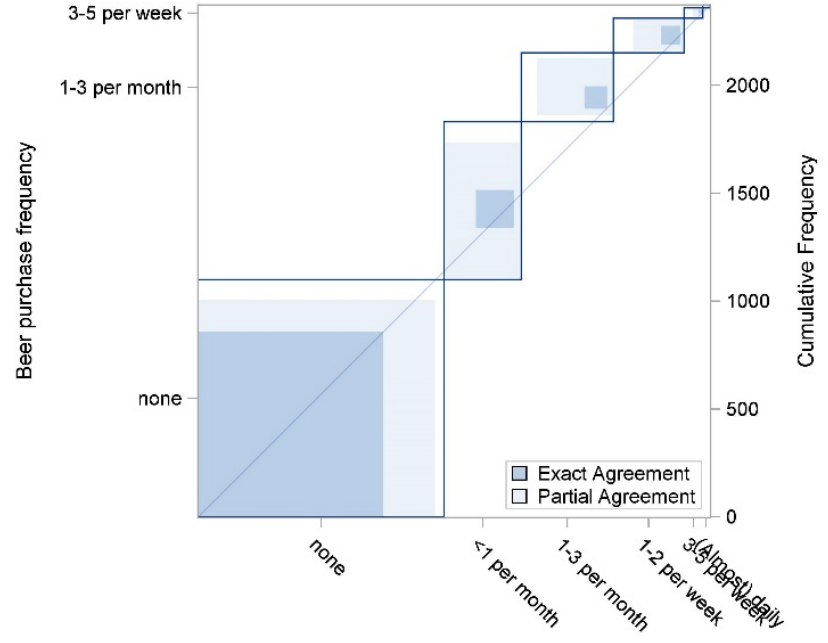

Self-reported beer drinking frequency

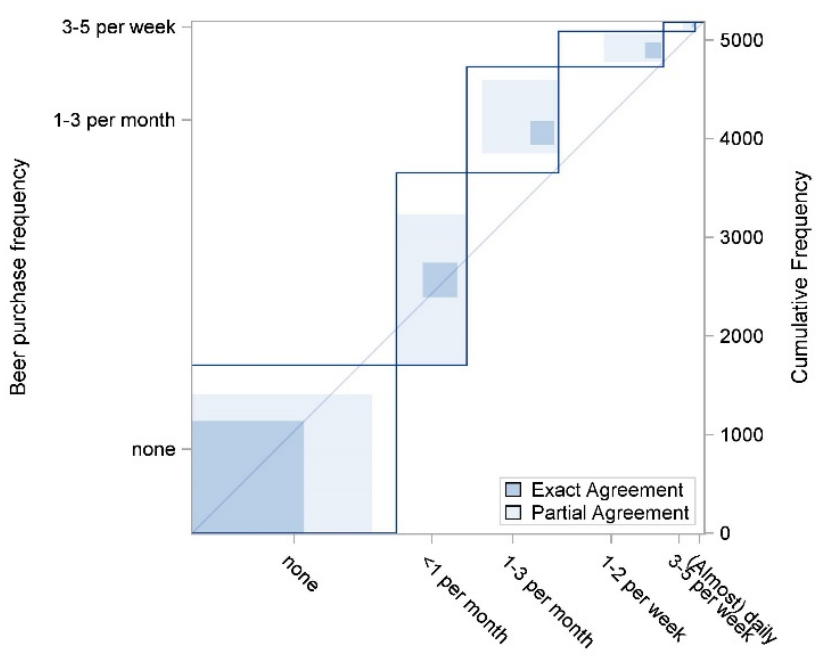

Self-reported beer drinking frequency

Figure 2. Beer purchase frequency during 6 months ( $y$-axis) by self-reported beer drinking frequency ( $x$-axis) among those with $61-100 \%$ degree of loyalty. Left panel: single adult households; right panel: at least two adults in the household. Cumulative frequency refers to the cumulative number of observations falling in the categories up to the category in question. Unadjusted associations.

Combining adjacent categories of drinking frequency ( $<1$ day per month, 1-8 days per month, $>2$ days per week) improved agreement (Kappa $=.302 ; 95 \% \mathrm{Cl} .287, .316)$. In single adult households that reported at least $61 \%$ degree of loyalty (Figure 2 left panel), the agreement was fair (Kappa=.319; 95\% Cl .294, .344) for the six-category and moderate (Kappa $=.463 ; 95 \% \mathrm{Cl} .430, .497)$ for the three-category variable. In this group, the agreement was excellent for the "none at all" -category: the rectangle is largely colored with darker shade of blue. In households with at least two adults (Figure 2 right panel), the proportion with exact agreement was substantially smaller. This difference to single-adult-households was particularly evident in the "none" -category.

\subsection{Group differences in agreement}

\subsubsection{The degree of loyalty}

The Poisson regression model indicated $61 \%$ less beer purchase days than self-reported beer drinking days among the most loyal customers. The disparity between purchase and drinking days was greater among those reporting lesser degree of loyalty: in the group reporting less than $20 \%$ loyalty, with the same number of drinking days, the proportion of purchase days was $22 \%$ of the amount in the group with at least $81 \%$ loyalty. Adjustment by the corresponding factor for each level of degree of loyalty (e.g., inverse of 0.22 ) improved both the association (Gamma $=.749,95 \% \mathrm{Cl} .732, .766$ ) and agreement (Kappa=.367, 95\% Cl $.352, .382$ ) of the three-category purchase frequency and drinking frequency.

\subsubsection{Socio-demographic factors}

The models were adjusted for the degree of loyalty and the differences between groups refer to differences relating to the same number of self-reported drinking days. Considering the number of drinking 
days, men had $9.0 \%$ less beer purchase days than women $(p<.001)$. Compared with one adult households, $21.8 \%$ fewer purchases were made in two adult households $(p<.0001)$. Those sixty years of age or older made $10.8 \%$ less purchases than those aged 30 to 59 years $(p<.0001)$. Compared with those having a Master's degree, those with primary education had $31.0 \%$ more purchase days $(p<.0001)$, those having a secondary degree $30.1 \%$ more $(p<.0001)$ and those with a Bachelor's degree $15.1 \%$ more purchase days $(p<.0001)$. Unemployed had $36.3 \%$ more $(p<.0001)$ and retired had $15.0 \%$ less purchase days than those employed $(p<.0001)$. The model incorporating all the above factors showed no major changes to the analyses that included only the factor in question and the degree of loyalty.

\section{Discussion}

Alcohol purchase data can be used to estimate alcohol drinking frequency. The association between beer purchase frequency and self-reported beer drinking frequency was good; however, the agreement between purchase frequency and drinking frequency was only fair. Limiting the data to single adult households that reported at least $61 \%$ degree of loyalty and collapsing the frequency categories to three instead of six improved the agreement to good. Severe misclassification occurred in $13 \%$ of the cases; this is considerably better than 17\% found in food consumption (FFQ) in Finland and Lithuania (Petkeviciene et al., 2009) and $48 \%$ in FFQ-based alcohol drinking frequency among pregnant women (Erkkola et al., 2001). With the same number of beer drinking days, there were less purchase days among men, those living in two adult households, those 60 years or older, those with more education and those employed or retired.

The study strengths include a large sample size, objective measurement of purchase and lack of recall or reporting error in purchases (Tin et al., 2007; Johansen et al., 2006). Drinking frequency, however, was subject to reporting errors, and this may partly explain lack of agreement between the two measures. Participation rate was low and a possible source of selection bias. The participants were unaware of their purchase history use at the time of data collection (Uusitalo et al., 2019). Lacking a 'golden standard', only relative validity could be studied. In nutrition research, objectively documented household food purchases yielded a reasonably accurate estimate of overall diet quality (Appelhans et al., 2017). Our results show this to be true also concerning beer purchases. However, many consumers distribute their purchases between different retailers; data from a single retailer does not include all purchases. Beer drinking takes place also outside home, i.e. in restaurants and bars. Purchase data do not necessarily describe the drinking of the person who purchases the beer: someone else may drink it, or someone else may have bought the beer the study participants drank. Our finding that agreement is stronger among single adult households suggests that this is common. In Finland, the grocery market is highly centralized with the largest operator having a market share as high as 47\% (Finnish Grocery Trade Association, 2019). Centralization provides a good opportunity to study heterogeneous populations through data from a single grocery retail chain.

Information on beer purchase days derived from the loyalty card database can be used to rank people according to their drinking frequency, and to estimate beer drinking frequency with fair to good accuracy. Accuracy depends on how big a share of grocery purchases a person makes from the grocery retailer in question; correction factors are needed for those with small shares. This type of data that contains detailed information on what, where, when, and who bought alcoholic beverages enables longitudinal tracking of the purchase behaviors of a household, and even a single customer, over time. Compared with market surveys, loyalty card data give a possibility to link the purchases to, e.g., age, education and location of the cardholder. These data are potentially important when using grocery purchase data for health policy purposes. As an added benefit, data collection is cost effective since it is recorded automatically at the store check-out.

Funding source The project received no specific funding and was conducted as part of the authors' duties in their respective institutions. 
Contributors All authors participated in the design and planning of the study. TL was the major contributor in writing the manuscript and JN conducted the data analysis. All authors reviewed and edited the manuscript and approved the final version of the manuscript.

Declaration of Competing Interest The authors declare that they have no competing interests.

\section{References}

Aledavood, T., Torous, J., Triana Hoyos, A.M., Naslund, J.A., Onnela, J-P., Keshavan, M., 2019. SmartphoneBased Tracking of Sleep in Depression, Anxiety, and Psychotic Disorders. Curr. Psychiatry Rep. 21 (7), 49.

Appelhans, B.M., French, S.A., Tangney, C.C., Powell, L.M., Wang, Y., 2017. To what extent do food purchases reflect shoppers' diet quality and nutrient intake? Int. J. Behav. Nutr. Phys. Act., 14 (1), 46.

Bandy, L., Adhikari, V., Jebb, S., Rayner, M., 2019. The use of commercial food purchase data for public health nutrition research: A systematic review. PLoS One 14 (1), e0210192.

Bangdiwala, S.I., Shankar, V, 2013. The agreement chart. BMC Med Res Methodol. 2013; 13: 97. Published online 2013 Jul 29. doi: 10.1186/1471-2288-13-97

Becker, W., 2001. Comparability of household and individual food consumption data--evidence from Sweden. Public Health Nutr 4 (5B), 1177-1182.

Carroll, J.K., Moorhead, A., Bond, R., LeBlanc, W.G., Petrella, R.J., Fiscella, K., 2017. Who Uses Mobile Phone Health Apps and Does Use Matter? A Secondary Data Analytics Approach. J. Med. Internet Res. 19 (4), e125.

Erkkola, M., Karppinen, M., Javanainen, J., Räsänen, L., Knip, M., Virtanen, S.M., 2001. Validity and reproducibility of a food frequency questionnaire for pregnant Finnish women. Am J Epidemiol. 154(5):46676.

Finnish Grocery Trade Association, 2019. Finnish Grocery Trade 2019. Helsinki.

Goodman, L., Kruskal, W., 1954. Measures of Association for Cross Classifications. Journal of the American Statistical Association 49 (268): 732-764. doi:10.2307/2281536

Johansen, D., Friis, K., Skovenborg, E., Gronbaek, M., 2006. Food buying habits of people who buy wine or beer: cross sectional study. BMJ 332(7540): 519-22.

Kesse-Guyot, E., Assmann, K., Andreeva, V., Castetbon, K., Méjean, C., Touvier, M., Salanave, B., Deschamps, V., Péneau, S., Fezeu, L., Julia, C., Allès, B., Galan, P., Hercberg, S., 2016. Lessons Learned From Methodological Validation Research in E-Epidemiology. JMIR public Heal. Surveill. 2 (2), e160.

Korkalo, L., Vepsäläinen, H., Ray, C., Skaffari, E., Lehto, R., Hauta-Alus, H.H., Nissinen, K., Meinilä, J., Roos, E., Erkkola, M., 2019. Parents' Reports of Preschoolers' Diets: Relative Validity of a Food Frequency Questionnaire and Dietary Patterns. Nutrients. 2019 Jan 13;11(1). pii: E159. doi: 10.3390/nu11010159.

Landis, J.R., Koch, G.G., 1977. The measurement of observer agreement for categorical data. Biometrics 33 (1): 159-174. doi:10.2307/2529310. JSTOR 2529310. PMID 843571.

Livingston, M., Callinan, S., 2015. Underreporting in alcohol surveys: whose drinking is underestimated? J Stud Alcohol Drugs 76, 159-164.

Mäkelä, P., Härkönen, J., 2017. Alcohol consumption in Finland has decreased: but whose consumption and what kind of consumption? Yhteiskuntapolitiikka 82: 513-26. 
Mooney, S.J., Westreich, D.J., El-Sayed, A.M., 2015. Commentary: Epidemiology in the era of big data. Epidemiology 26 (3), 390-4.

Nevalainen, J., Erkkola, M., Saarijärvi, H., Nappila, T., Fogelholm, M., 2018. Large-scale loyalty card data in health research. Digit Health. 2018;4. doi:10.1177/2055207618816898

Petkeviciene, J., Similä, M., Becker, W., Kriaucioniene, V., Valsta, L.M., 2009. Validity and reproducibility of the NORBAGREEN food frequency questionnaire. Eur J Clin Nutr. 63(1):141-9.

Pietilä, J., Helander, E., Korhonen, I., Myllymäki, T., Kujala, U.M., Lindholm, H., 2018. Acute Effect of Alcohol Intake on Cardiovascular Autonomic Regulation During the First Hours of Sleep in a Large Real-World Sample of Finnish Employees: Observational Study. JMIR Ment. Heal. 5 (1), e23.

Salathé, M., 2018. Digital epidemiology: what is it, and where is it going? Life Sci. Soc. Policy 14 (1), 1. 2018.

Sierosławski, J., Moskalewicz, J., Mäkelä, P., et al., 2016. Alcohol consumption. In: Moskalewicz, J., Room, R., Thom, B., (eds.). Comparative monitoring of alcohol epidemiology across the EU. Baseline assessment and suggestions for future action. Synthesis report. Warsow: Parpa.

Tin, S.T., Mhurchu, C.N., Bullen, C., 2007. Supermarket Sales Data: Feasibility and Applicability in Population Food and Nutrition Monitoring. Nutr. Rev. I. 65 (1), 20-30.

Tolonen, H., Honkala, M., Reinikainen, J., Härkänen, T., Mäkelä, P., 2019. Adjusting for non-response in the Finnish Drinking Habits Survey. Scandinavian Journal of Public Health 47(4):140349481984089

Uusitalo, L., Erkkola, M., Lintonen, T., Rahkonen, O., Nevalainen, J., 2019. Alcohol expenditure in grocery stores and their associations with tobacco and food expenditures. BMC Public Health 19(1).

Vuorinen, A., Erkkola, M., Fogelholm, M., Kinnunen, S., Saarijärvi, H., Uusitalo, L., Näppilä, T., Nevalainen, J., 2020. Characterization and correction of bias due to nonparticipation and the degree of loyalty in largescale Finnish loyalty card data on grocery purchases. J Med Internet Res 2020;10.2196/18059.

Yearbook of Alcohol and Drug Statistics 2019, 2020. Helsinki: Official Statistics of Finland. 